Article

\title{
Electromagnetic Energy Harvesting Technology: Key to Sustainability in Transportation Systems
}

\author{
Mohammadreza Gholikhani *, Seyed Amid Tahami, Mohammadreza Khalili and \\ Samer Dessouky \\ Department of Civil and Environmental Engineering, University of Texas at San Antonio (UTSA), San Antonio, \\ TX 78249, USA \\ * Correspondence: mohammadreza.gholikhani@utsa.edu
}

Received: 12 August 2019; Accepted: 5 September 2019; Published: 8 September 2019

\begin{abstract}
The convergence of concerns about environmental quality, economic vitality, social equity, and climate change have led to vast interest in the concept of sustainability. Energy harvesting from roadways is an innovative way to provide green and renewable energy for sustainable transportation. However, energy harvesting technologies are in their infancy, so limited studies were conducted to evaluate their performance. This article introduces innovative electromagnetic energy harvesting technology that includes two different mechanisms to generate electrical power: a cantilever generator mechanism and a rotational mechanism. Laboratory experimental tests were conducted to examine the performance of the two mechanisms in generating power under different simulated traffic conditions. The experimental results had approximately root mean square power $0.43 \mathrm{~W}$ and $0.04 \mathrm{~W}$ and maximum power of $2.8 \mathrm{~W}$ and $0.25 \mathrm{~W}$ for cantilever and rotational, respectively. These results showed promising capability for both mechanisms in generating power under real traffic conditions. In addition, the study revealed the potential benefits of energy harvesting from roadways to support sustainability in transportation systems. Overall, the findings show that energy harvesting can impact sustainable transportation systems significantly. However, further examination of the large-scale effects of energy harvesting from roadways on sustainability is needed.
\end{abstract}

Keywords: sustainability; energy harvesting; renewable energy; electromagnetic energy; sustainable transportation; sustainability indicators

\section{Introduction}

The convergence of concerns about environmental quality, economic vitality, social equity, and climate change have led to vast interest in the concept of sustainability [1]. The concept of sustainability has broadened to include social, environmental, and economic dimensions [2]. Sustainable development is viewed as change that improves quality of life and conserves time and natural resources [3]. However, there is no universally accepted definition of sustainability [4]. One of the most accepted definitions is from the Brundtland Commission, which defined sustainability as "meet[ing] the needs of the present without compromising the ability of future generations to meet their own needs" [5]. Currently, however, global developments are causing environmental damages and depleting resources [6]. Transportation, which is one of the most important parts of development, also contributes to environmental issues and energy waste [7]. Thus, sustainable transportation is an essential component of sustainable development [8].

Many reasons why existing transportation networks are not sustainable exist [9], such as finite fossil fuel reserves serving as a main source of energy; the negative impact of emissions on the environment and urban quality; air pollution, excessive fatalities, and injuries due to vehicle accidents; 
high congestion in transportation facilities; and more [10-12]. A sustainable transportation system must be safe, affordable, and healthy and incorporate renewable resources and limited emissions [13]. According to the Center for Sustainable Transportation [14], a sustainable transportation system:

- Fulfills the basic needs of access of individuals and societies in a manner that is safe, that is consistent with the environment, and that provides equity between generations.

- Operates efficiently, offers different modes of transport, and is cost efficient.

- Minimizes renewable resource consumption, limits land use and noise production, recycles its components, and controls the level of emissions and waste to meet the absorption capability of the planet $[15,16]$.

Significant efforts are being made to attain a more sustainable transportation system $[17,18]$. A growing number of researchers, policy makers, and practitioners are working on creating sustainability in transportation systems [12]. However, any change in the transportation sector might lead to changes in other sectors and consequently affect sustainable development [17]. Thus, valid sustainability indicators are needed to monitor transportation sustainability [19] and evaluate the effects of transportation system changes on future sustainable development [17]. Some researchers have simulated future projections to forecast development in the transportation system and relevant indicators [17]. Various attempts have also been made to provide a list of sustainable transportation indicators e.g., [20,21]. These sustainable transportation indicators provide a solid basis for decision- making related to sustainable development at all levels [19] (indicators are discussed in more detail in Section 6.2). Energy is a central component of transportation indicators because energy and related issues play an important role in the transition toward a sustainable society and transportation system [22]. Any effort in power generation technologies can impact different aspects of sustainability.

The energy consumption tied to transportation is a considerable portion of the overall energy consumption in the world $[7,23,24]$. The worldwide transportation sector has become the second largest greenhouse gas emitting sector, mainly due to fossil fuel burning [23,24]. Thus, renewable energies have received significant attention due to their green and non-polluting nature [25]. Renewable energy improves the ability to maximize transportation-related environmental performance and minimize adverse impacts [26], while also having a major impact on economic growth [27].

Generating renewable energy from the roadway infrastructure, which is called roadway energy harvesting, is an innovative idea. Generally, energy harvesting involves converting existing unused environmental energy sources into useful energy for industries [28]. In this study, an innovative electromagnetic device was developed to harvest energy from roadways. Laboratory experimental tests were conducted to evaluate the device's performance in different aspects. The presented technology to harvest energy from roadways can be a part of the solution to overcome the growing challenge of energy demands in transportation. In addition, the potential effect of the device on transportation sustainability was reviewed.

\section{Study Objectives}

The goal of this study was to develop and evaluate electromagnetic energy harvesting prototypes in transportation systems for two different new mechanisms to generate and harvest electric power from passing vehicles. Moreover, the effects and benefits of the technology on sustainability in transportation systems was explored. The specific objectives of the study included the following:

- Introducing the concept of sustainability in transportation systems.

- Designing and fabricating prototypes with two mechanisms.

- Conducting tests to examine the power generation capability of each mechanism.

- Investigating the effects of traffic loading on the power generation potential.

- Evaluating the effect of electromagnetic energy harvesting in roadways on transportation sustainability. 


\section{Literature Review of Energy Harvesting from Roadways}

Energy harvesting from ambient sources has become an important field of research due to the drawbacks of traditional energy resources such as fossil fuels [21]. For instance, energy harvesting technologies generate electrical power from ocean waves [29], thermal energy [30,31], solar energy [32,33], vibration [34-36], human motions [37], and wind [38,39]. Transportation and pavement engineering is one field in which energy harvesting is attracting much attention [22]. In transportation, energy harvesting can solve the energy resource challenge for electrical equipment in transportation infrastructure-such as wireless sensors-and thereby improve management and safety [24]. Energy harvesting technologies include piezoelectric-based modules [40,41], asphalt solar collectors [42], thermoelectric systems [43], electromagnetic systems [44], and installed solar panels in the pavement [45].

These technologies are integrated into a body of pavements in roadways to harness energy for various purposes, all of which lead to a reduction in the consumption of fossil fuel resources. Some of them generate electricity to run pavement health monitoring systems, traffic monitoring systems, and infrastructure utilities, such as lighting, which are substantial for sustainable transportation [46]. Energy harvesting can also be a reliable source of energy in areas without an energy grid [47]. Signs and lighting fed by energy harvesting sources can notably improve safety in remote areas by mitigating lighting-related accidents [48].

Other applications of energy harvesting technologies in roadways include dissipating heat and controlling pavement distresses [49], mitigating urban heat islands (UHIs) [50], and melting snow in winter seasons [51]. These applications have direct effects on transportation sustainability. For instance, melting snow in cold regions presents one of the biggest challenges to traffic safety during winter seasons [52-54]. Crucially, energy harvesting technologies provide sustainable mechanisms for ice and snow melting on roadways, while traditional methods, such as the application of snow melting agents [55] and mechanical snow removal [56], provide only temporary solutions and are costly and hazardous for environmental and roadway infrastructures [57]. Conversely, energy harvesting can mitigate the heat of pavement. A heated pavement surface is vulnerable to distresses, such as rutting and losing its functionality [58]. Mitigating this heat increases the service life of the pavements [43] and decreases the cost and time of maintenance [59]. Reducing pavement temperature in urban areas also mitigates the UHI effects [60]. Lower pavement temperatures reduce thermal radiation from pavement surfaces $[61,62]$. These advantages help promote the sustainability of transportation systems. In the next section, the electromagnetic energy harvesting technology will be described in detail. Subsequently, the developed electromagnetic energy harvester prototype will be presented.

\section{Electromagnetic Energy Harvesting Technology}

Electromagnetic technology is a function of Faraday's law [63], and electromagnetic energy harvesting technology converts mechanical energy into electrical power through electromagnetic mechanisms [64]. The general form of Faraday's law, the Maxwell-Faraday equation, notes that a time-varying magnetic field and spatially electric field always accompany each other [65]. Electromagnetic technology is widely utilized in different industries, and energy harvesting is one field that uses significant electromagnetic technology. Electromagnetic energy harvesting generates power from multiple sources, such as ocean waves [66-69], wind [70], backpacks [71,72], human motion [73], walking [74], vehicle suspensions [75], and railroads [76-79].

Based on the acceptable performance of this technology in the aforementioned fields, researchers have studied its application in roadway infrastructure [80]. The technology has higher efficiency and power output in applications with larger deflections [67]. On the other hand, the technology must avoid an interruption in transportation. Therefore, for installation in roadways, the electromagnetic technology should be installed in locations that are both subjected to large deflections and cause minimum interruption to traffic flow simultaneously. Locations with speed bumps are one such ideal option. Speed bumps are used to reduce the risk of accidents in low-speed zones and pedestrian 
crossings by controlling vehicle speed [81]. In these areas, vehicle speed must be reduced, and the vehicles also generate large deflections as they go over the speed bumps [82]. Currently, a huge amount of energy is wasted as vehicles pass over the speed bumps [83]. That wasted energy can be captured and converted to a useful kind of energy by electromagnetic energy harvesting technology. Thus, the installation of an electromagnetic energy harvester under speed bumps simultaneously contributes to addressing both safety and energy factors in sustainable transportation systems.

The basic principle in all mechanisms in the electromagnetic energy harvesting devices is to trigger relative movement between a conductor and a magnetic field (Faraday's law) by utilization of the induced movement from passing vehicles [84]. The mechanisms include a rack-and-pinion system [85,86], cam-arm system [87], roller-chain system [88], hydraulic power system [89], statortranslator [90], rotational motion [91], chain-sprocket system [92], and compression of air upon passage of a vehicle [93]. Combinations of these systems have been used in some studies (e.g., rack- and-pinion and hydraulic systems) [94]. In this study, two mechanisms were developed-a cantilever energy harvester and a rotational mechanism — that both generate power due to relative movements of magnets and electrical coils. These mechanisms were evaluated separately as two completely independent prototypes. However, the structural parts are mutual, and for experiments, the power generation parts of mechanisms replaced each other. It must be noted that the prototype design functions to perform as a speed bump in addition to generating power.

\section{Materials, Design, and Experimental Tests}

This section presents the two mechanism components and materials used for design and fabrication. Laboratory experimental tests, including test setup and results, are also discussed. Since the study objectives included a preliminary evaluation of the possibility of generating power with these mechanisms, the prototypes were fabricated in small sizes.

\subsection{Design and Fabrication of Mechanisms}

For both mechanisms, the prototype was designed according to two aspects: structure and power generation. The power generation component was designed to capture the wasted energy from a passing vehicle through its top plate and use it to generate electrical power. The structure was designed to support the entire prototype under heavy loads of passing vehicles.

The structure, which was the same for both mechanisms, included supports, compression springs, a top plate, and a bottom plate. However, the top plate and compression springs are mutual for both power generation and the structural frame. The bottom plate was a platform onto which the other parts were installed. The bottom plate conveyed the stress of supports to the foundation under it. The properties of aluminum, including low density, water resistance, acceptable strength, and resistance to corrosion (except its surface), make it an appropriate option for the bottom plate. Cylinder supports were installed to maintain structural integrity and control the top plate movement. These supports also protect other components from direct contact with the applied loads. Due to large loads in service life and harsh environment conditions, the cylinder supports were made of steel.

Compression springs were connected to the top plate and placed inside the supports. Compression springs are crucial elements of the device due to their tasks. Springs help the top plate move smoothly under the loads, which is important to preserve parts from high stress and to allow drivers to feel less uncomfortable. These springs returned the top plate to its original position and completed the cycle of loading. The springs were made of steel to tolerate frequent wheel loads. Rods connected to the top plate moved inside holes in the supports to guide the top plate's movement in a fixed vertical direction. 
As mentioned, the top plate was the only part directly in contact with loads. Thus, the material of the top plate had to endure the impact of these large loads. In addition, the top plate was meant to replace the speed bump while capturing wasted energy. Therefore, the designed profile had to be similar to a traditional speed bump. However, in this laboratory experiment, an aluminum plate with $25 \mathrm{~mm}$ thickness was chosen as the top plate. To test the prototype using standard laboratory equipment, $440 \mathrm{~mm}$ length was chosen to fit the prototype inside the testing equipment. The width of the top plate was $300 \mathrm{~mm}$, similar to a conventional speed bump. However, for further study and installation in the field, the length of the top plate would need to be equal to a typical roadway lane width $(3.75 \mathrm{~m})$ to capture the load of the passing vehicles. Figure 1 illustrates the structural design with the power generation components of both mechanisms.

(a)

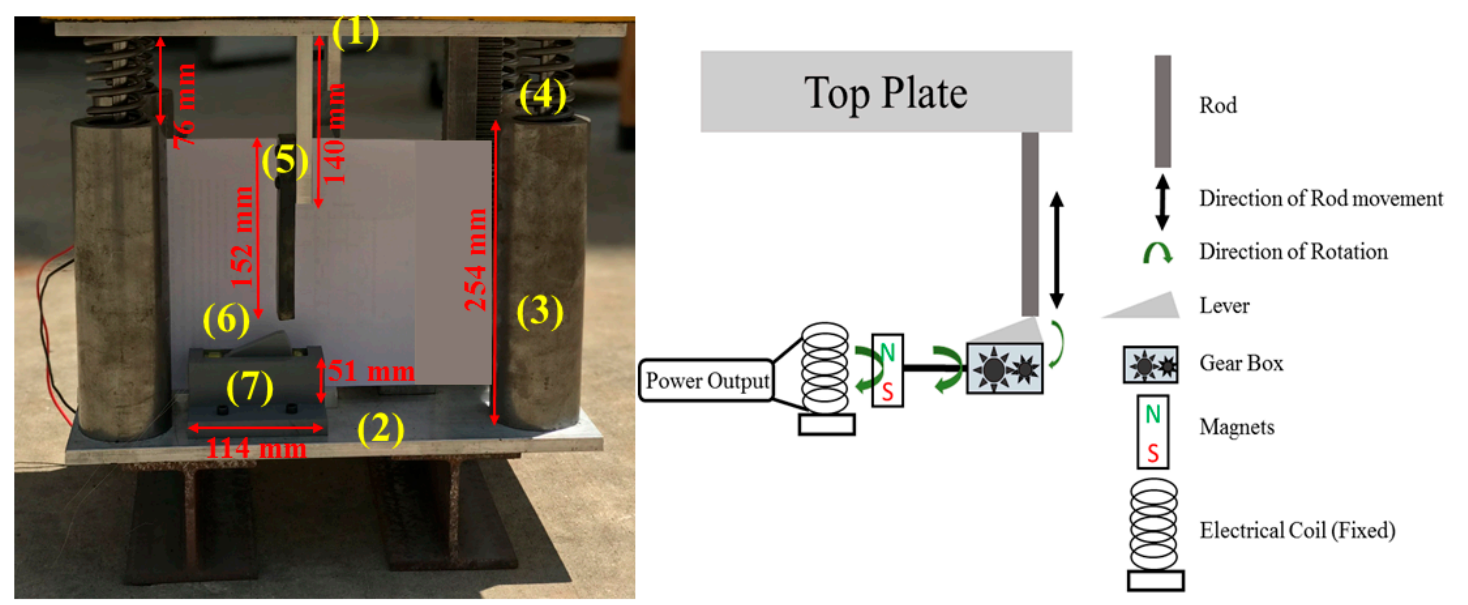

(b)

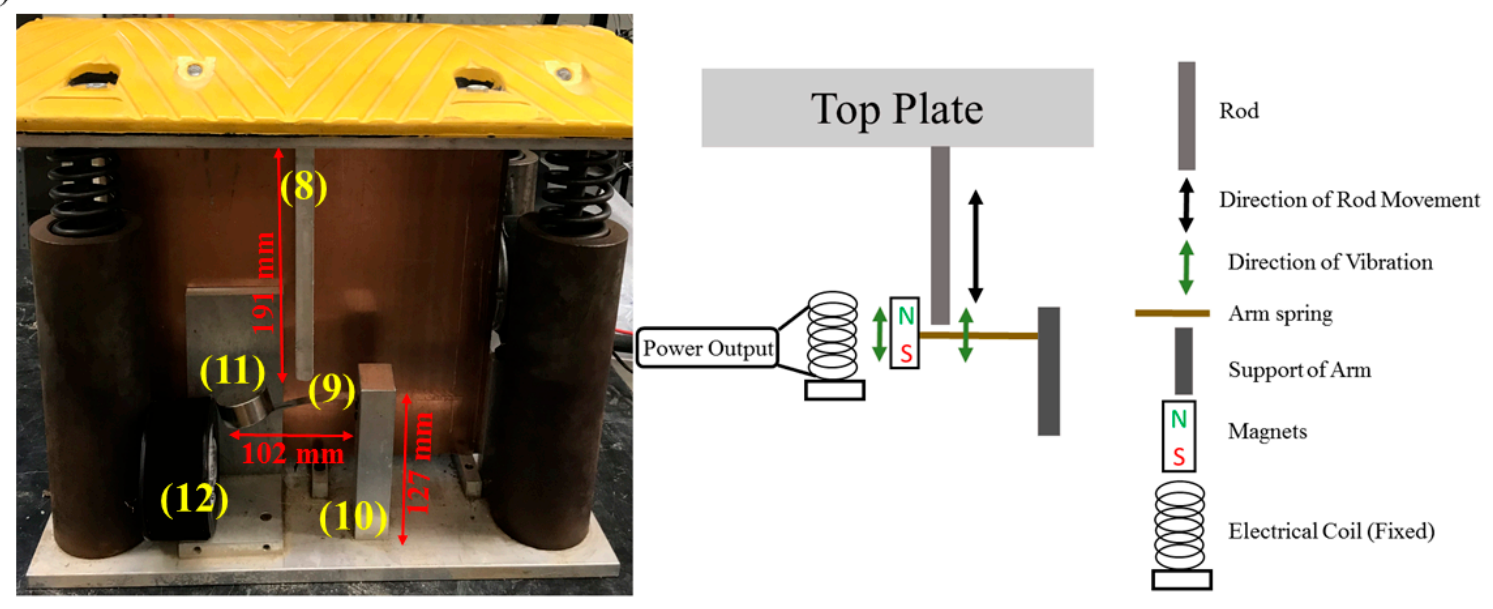

Figure 1. The fabricated mechanism components. (a) The schematic, structural and power generation components of the rotational mechanism: (1) top plate; (2) bottom plate; (3) cylindrical support; (4) compression springs; (5) two-part rod; (6) lever; and (7) box that includes magnets, coils, gears, and torsional springs; (b) The power generation components and schematic of the cantilever mechanism:

(8) rod; (9) spring arm; (10) arm support; (11) magnets; and (12) electrical coil.

\subsubsection{The Power Generation Component of the Rotational Mechanism}

In the rotational mechanism, the power generation part included a two-part rod, set of gears, torsion springs, circular magnets, and electrical coil. Figure 1a represents the rotational mechanism and its schematic. In this mechanism, the two-part rod is connected to the top plate and moves downward and upward with it. When the rod moves downward, it pushes the lever downward, which 
is connected to the set of gears. This set of gears receives the vertical movement from the lever and converts it to rotations and conveys it to the permanent magnet. At the same time, they also amplify the amount of rotations with the ratio between the gears. The rotation magnets generate a time-varying magnetic field in the electrical coil. According to Faraday's law, this time-varying magnetic field produces an electrical power in the electrical coil. When the rod moves upward, the torsion springs return the lever to its position. However, due to the study's mechanism design, in this recovering process, it did not generate power, but it is possible to change the design and generate power, even in the recovering process.

The rod was made of two parts: a hard part made of aluminum and a soft part made of rubber. The reason the soft part was added was to control the applied stress on the lever and maximize the generated power. The soft part allowed us to keep it very close to the lever to push the lever down with a small displacement of the top plate generated by a small load. When the load is higher and the top plate displacement is higher than the allowed displacement of the lever, the soft part will bend and prevent the higher value of the displacement to the lever to be applied.

\subsubsection{The Power Generation Component of the Cantilever Generator Mechanism}

In the cantilever generator mechanism, the power generation part consisted of a magnet, electrical coil, spring arm, rod, and support for the arm spring. The components and schematic are illustrated in Figure $1 b$.

The aluminum rod was connected to the top plate in order to move with it. When the top plate moves downward, the rod moves downward correspondingly and pushes the spring arm down. The spring arm was a cantilever, which was maintained with its supports. On the free side of the cantilever arm, a permanent magnet was installed. The magnet was neodymium-iron-boron alloy (NdFeB) with $40 \mathrm{~mm}$ diameter and $20 \mathrm{~mm}$ thickness. The electrical coil was installed next to the magnets. The coil consisted of a wire of $1432 \mathrm{~m}$ length and $80 \mathrm{~mm}$ diameter. When the arm is pushed by the rod, the magnets move relatively to the electrical coil and as a result induce electricity in a wire of the coil. In the recovering process of the top plate, the rod moves upward and allows the arm to return to its first position. In this step, the magnet and the electrical coil have a relative movement, which leads to inducing electrical power.

\subsection{Laboratory Testing}

The ability of the two mechanisms to generate electrical power was studied in laboratory experiments. A Universal Testing Machine was used to simulate traffic loading conditions by applying repetitive loads with different frequencies. A multifunction National Instruments Data Acquisition Card (NI DAQ) was used to record the power outputs. The RS-200 W resistance substitution box was used as an external resistor.

A speed bump will experience different loads in its service life due to the different weights of passing vehicles. Thus, to simulate the loads of vehicles' wheels, different loads $(3,5$, and $10 \mathrm{kN})$ in Harvesine waveform were applied. Loading times and unloading time were chosen to reflect slowing vehicles just before passing over the speed bump. The speed of the vehicle was assumed to be constant. Therefore, three loading-unloading cycles of 300,600, and $900 \mathrm{~ms}$ were arbitrarily selected to account for the loading-unloading. All the laboratory tests were conducted at room temperature $\left(\sim 25^{\circ} \mathrm{C}\right)$. Figure 2 represents the laboratory test setup and power measuring device. 

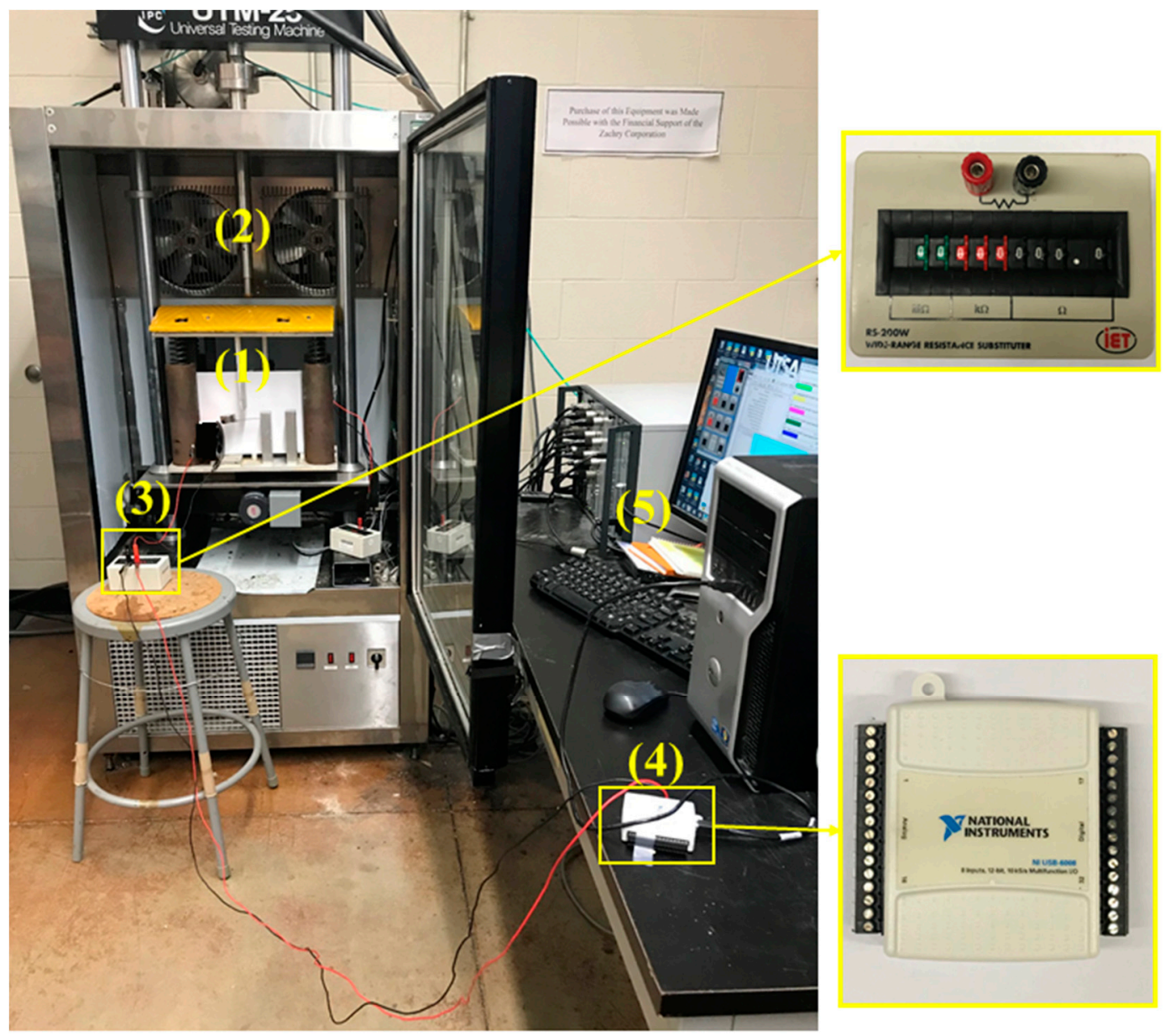

Figure 2. Laboratory test setup and power measuring device: (1) device, (2) UTM, (3) resistance substitution box, (4) NI DAQ board, and (5) DAQ system to record outputs.

\subsection{Experimental Results, Analysis, and Discussion}

The power outputs of each mechanism under different loading conditions were measured. Both mechanisms showed a potential to generate power under these applied loads. Both mechanisms had their own output patterns, but the output patterns of each mechanism were similar under different conditions. Figure 3 presents the general pattern of both mechanisms within three cycles of loadingunloading. Figure 3 also illustrates a single cycle loading-unloading and corresponding to top plate movements. In phase one of the cycle (period 1 in Figure 3) the top plate is going downward, while in phase two (period 2 in Figure 3) the top plate is moving upward. In Figure 3a, it can be observed that the cantilever mechanism generated electrical power in both the downward and upward movements of the top plate because in both movements relative movements between magnets and electrical coils were generated. The power output had one peak in both the downward and upward movements, which corresponded to the peak rate of movements between the magnet and the coil. The power output shows that the bouncing arm also led to generation of power. In addition, it shows the damping process of the bouncing arm. 


\section{(a)}

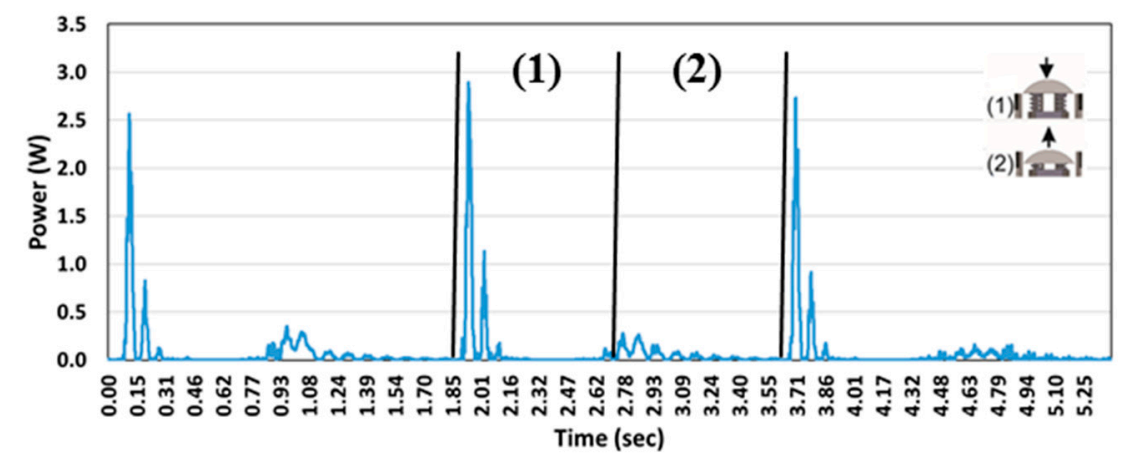

\section{(b)}

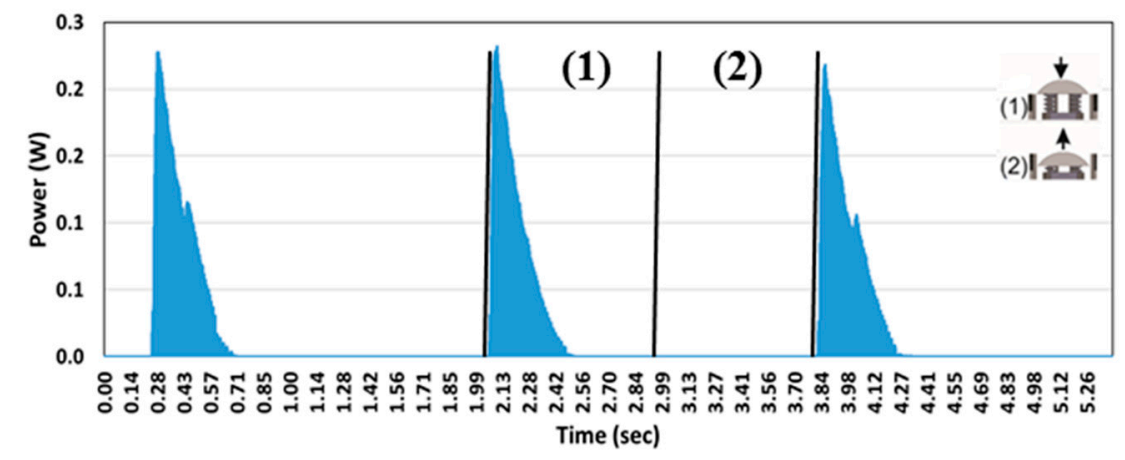

Figure 3. Power output under multiple loading cycles and top plate movement directions in one cycle: (a) cantilever mechanism; (b) rotational mechanism.

Figure $3 b$ illustrates that the rotational mechanism generated electrical power only in downward movements of the top plate because, as mentioned, the mechanism could only convert downward movements to relative movements between the magnet and the electrical coil due to its design. However, the mechanism could generate power in upward movements by changing its design. The power output peak corresponds to the maximum angular velocity of the magnet, which interprets the maximum rate of relative movements between the magnets and coil.

According to the results in Figure 3, the maximum output power is $2.8 \mathrm{~W}$ and $0.25 \mathrm{~W}$ for cantilever and rotational mechanisms, respectively. It is expected that the output of the proposed will increase significantly as these new mechanisms undergo optimization. Other studies reported other ranges of maximum power for current technologies, $42 \mathrm{~mW}$ [95], $1.8 \mathrm{~W}$ [96], and $220 \mathrm{~W}$ [45] for thermoelectric, piezoelectric, and photovoltaic panel. By comparison between the output powers of these technologies, the proposed mechanisms had an acceptable performance at this early stage of development.

Figure 4 presents the root mean square of the power outputs of the cantilever and rotational mechanisms in different conditions of loadings. As can be seen, both mechanisms follow the same pattern. The output power increased by increasing the magnitude of load. In both mechanisms, $10 \mathrm{kN}$ loads resulted in the maximum output because, by increasing the load, the relative movements in both mechanisms increased. However, the effects of the ratio of load magnitudes were different. For instance, the output power decreased by increasing the loading-unloading time. If the load is applied frequently, a smaller time loading means higher frequency, so a higher frequency led to higher output in both mechanisms. It is worth noting that the magnitudes of mechanisms are different. The power output of the cantilever mechanism is approximately 10 times that of the rotational mechanism, primarily because the components used in the rotational mechanism are very small, while the components of the cantilever mechanism are much larger in comparison. For example, the electrical coil of the cantilever 
mechanism is much larger than the rotational electrical coil. The maximum output power of rotational and cantilever mechanisms were $0.04 \mathrm{~W}$ and $0.43 \mathrm{~W}$, correspondingly. In general, the results in Figure 3 show that both mechanisms can generate electrical power in different conditions.
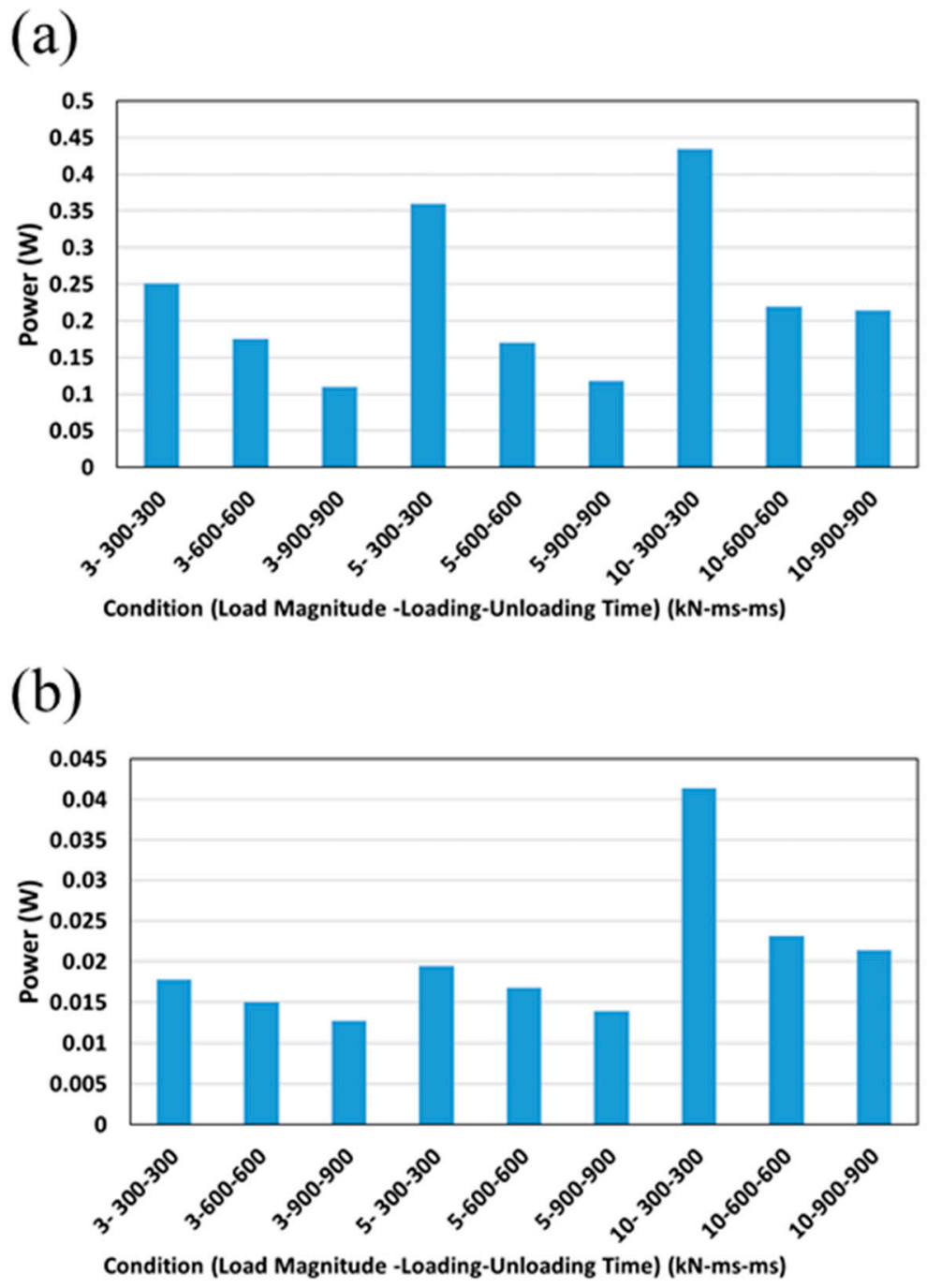

Figure 4. Root mean square of power output under different loading conditions: (a) cantilever mechanism; (b) rotational mechanism.

It is important to note that the design and parts used were small in scale since the study was preliminary. Future studies will need to utilize larger parts. Also, only one set of power generation parts was included in the prototype assembly for laboratory experimentation. It is envisioned that the final design will include multiple parts to amplify the power output for each passage. In addition, based on the above results, it seems necessary to optimize the design or introduce new or more effective components to maximize power output generation. For instance, by changing the design, the rotational mechanism could generate power in the upward movements.

In addition, as mentioned before, the top plate shape will be similar in design to the conventional speed bump, which will allow it to control traffic speed and impact safety. Potential locations for prototype installations are any locations with speed bumps, including parking garages, driveway entrances to buildings, school zones, and any other place where the speed of vehicles is controlled [80]. 


\section{Benefits to Sustainability Indicators and Strategies}

This section examines the benefits in general of electromagnetic energy harvesting from roadways and the specific benefits of the proposed energy harvesting prototype. Some current strategies and indicators of sustainability in transportation are introduced and effects of the electromagnetic energy harvesting technology are discussed.

\subsection{Benefits of the Technology in Strategies}

Various strategies have been proposed to develop sustainable transportation systems [17]. In general, strategies primarily focus on technological or behavioral alterations [17]. Behavioral strategies promote change in the manner of users of transportation systems and try to optimize them. For instance, car use can be reduced by combining trips, ride sharing, shifting to less polluting transportation modes, and so on [17]. Technological strategies are aimed at achieving sustainability in transportation by using technologies-such as reducing negative effects per car or kilometer [17]. In this study, the benefits of energy harvesting as a technological solution are discussed. Table 1 represents a partial list of some of the strategies that have been suggested for sustainable transportation [1]. This list shows the big picture of sustainability strategies in transportation. The effect of the proposed on sustainability technology is described by using the information in the table.

Table 1. Partial list of suggested strategies for sustainability in transportation systems [1].

\begin{tabular}{|c|c|}
\hline Area of Change & Suggested Change \\
\hline \multirow{4}{*}{ Road/Vehicle Operation Improvements } & $\begin{array}{l}\text { 1. Conventional Traffic Flow Improvements } \\
\text { a. Traffic Signal Timing } \\
\text { b. Ramp Metering } \\
\text { c. Flow Metering } \\
\text { d. Bottleneck Removal }\end{array}$ \\
\hline & $\begin{array}{l}\text { 2. Intelligent Transportation System Improvements } \\
\text { a. Smart Highways } \\
\text { b. Smart Vehicles } \\
\text { c. Accident/Incident Management } \\
\text { d. Routing and Scheduling Enhancements }\end{array}$ \\
\hline & 3. Driver Education \\
\hline & 4. Improved Logistics and Fleet Management \\
\hline
\end{tabular}

According to the list of strategies, electromagnetic energy harvesting in roadways can be a considerable source of energy for intelligent transportation system strategies. These strategies need infrastructures that depend on energy. Smart roadways need a lot of sensors and other kinds of devices that can operate with the proposed prototypes. The technology also will provide electrical power for the required infrastructures for smart vehicles, which need to communicate with other vehicles and roadway facilities. The proposed technology can make it possible to run the infrastructure in remote areas that lack accessibility to power networks.

Improved traffic monitoring systems powered by electromagnetic energy harvesters can create transportation systems that can supply enough data for planning the transportation system. The energy harvesting technology also will power the facilities that transfer data instantly and thus make real-time data possible. These real-time data can help to manage traffic flow properly, avoid the accumulation of traffic volume in specific locations, and minimize generated queues of vehicles. Moreover, routing/scheduling will be enhanced with recorded data from roadway networks. In addition, the collected data are required to remove bottleneck situations from roadways. Thus, better accident management is another benefit of the infrastructure provided by the power of energy harvesting technology in roadways. 
Further, energy harvesting technology can help flow metering in two ways. It can provide electrical power for metering devices, or by adding components, the energy harvester can have metering ability as an additional feature because it is already installed in a position-in the roadway-where it is appropriate for this purpose.

In general, the electromagnetic energy harvesting prototype will strengthen technological strategies and improve environmental quality, urban quality of life, and destination accessibility. It is especially worth repeating that one very important capability of energy harvesting is generating power in remote areas with limited access to power networks. This capability distinguishes this technology from other current technologies of power generation.

\subsection{Benefits of the Technology Regarding Indicators}

The effect of energy harvesting by electromagnetic energy harvesting technology on indicators offers another perspective that can provide a better understanding of its importance. As mentioned before, valid measurable indicators develop a comprehensive methodology to track and control transportation sustainability. Therefore, evaluating the effect of the proposed prototype and other electromagnetic energy harvesting on these factors provides a vision about the benefits of this prototype on transportation sustainability. To assess this perspective, multiple indicators suggested by Litman and Burwell [3] and Haghshenas and Vaziri [14] were chosen. These environmental, social, and economic indicators greatly cover key aspects of transportation sustainability.

\subsubsection{Environmental Benefits}

Energy harvesting technology has significant potential to be a green renewable resource of energy for transportation infrastructure. However, the technology is still in its infancy stage and large-scale production is not available. Compared to technologies that rely on fossil fuel, energy harvesting offers advantages that can greatly profit the environment. In this section, some of the benefits of the technology to the environment are briefly explained.

Electromagnetic energy harvesting technology produces no greenhouse gas emissions. Greenhouse gas emissions are one of the major causes of global climate change. Thus, this technology can help to reduce these gas emissions by a reduction in the burning of fossil fuel. Moreover, the technology operates without any other kind of air pollutants, which is another environmental factor of sustainability.

The technology's mechanism does not make considerable noise; thus, noise pollution will be negligible. The system does not need water for performing, and it will be insulated from the environment, which means no water pollution. Further, the proposed prototype will not affect wildlife habitat directly or indirectly due to its non-polluting nature. Thus, the technology helps to preserve the habitat.

If the prototype is installed in the pavement's structure, it does not need additional land for implementation. Furthermore, the technology generates power for road proximity areas; thus, the necessity for transferring infrastructure is minimal and land space for that is negligible. Therefore, it helps transportation systems have less land use impact on the environment.

These benefits show that using electromagnetic energy harvesting technology on roadways can positively impact the environmental indicators of sustainability in transportation systems.

\subsubsection{Social Benefits}

Energy harvesting technology can also have a significant effect on social indicators. One thing to bear in mind is that change in one indicator might cause changes in other indicators. For instance, a reduction in environmental and air pollution directly affects human health. Consequently, the first benefit is improved human health, which is a very important indicator for sustainable transportation [97].

The proposed technology also improves safety by reducing the amount of accidents on roadways. A reduction in accidents leads to a reduction in the number of fatalities and disabilities in accidents. 
Decreasing fatalities and disabilities therefore is another benefit of this technology in a sustainable transportation system.

Energy harvesting from roadways can be used to ensure that pavement health monitoring devices operate effectively. With these devices, the pavement will be monitored continuously. It allows agencies to track roadway distresses and thereby allocate their maintenance budget and facilities more effectively. Therefore, a roadway's level of service is maximized, which means that society receives better service. In addition, the better use of budgetary funds will lead to equity in society because the budget will be spent on infrastructure for all users.

The proposed prototype will also supply electrical power to a wide range of facilities, such as lighting, illuminations, and devices for people with disabilities. These facilities can improve service and safety for these users and other non-driver users of transportation systems (such as pedestrians). Consequently, equity for non-drivers and equity for disabled users are two more implications of this improvement.

\subsubsection{Economic Benefits}

As mentioned in all definitions of sustainable transportation systems, the economic aspect is one of the major concerns. In practice, however, emphasis has been on environmental and social aspects. This neglect of financial sustainability is an important omission [98]. Increasing financial sustainability in transportation systems provides a unique opportunity to allocate available budgets more efficiently to promote sustainability in environmental and social aspects [98]. There are some indicators that are directly impacted by electromagnetic energy harvesting technology.

The combination of high-quality pavements and smoother traffic flow on roadways facilitate effective freight and commercial transporting. Transportation systems with higher speed and affordability of freight have higher freight efficiency. Fright efficiency is one of the economic indicators for sustainability in transportation systems. Furthermore, smoother traffic flows without high volume traffic can minimize the average commute travel time.

In addition, continuous monitoring of the roadway's health prevents drops in the level of service of the roadways that need a huge budget to repair. As a result, facility costs as a sustainability indicator are lower in sustainable transportation systems.

Accidents, fatalities, and disabilities related to accidents have a huge financial and medical burden on societies. The proposed prototype can reduce accidents, especially on low-speed roadways and in remote areas. Thus, by reducing the number of accidents, these burdens will be eliminated, and numerous financial benefits will occur.

The reduction in the amounts of greenhouse gas emissions, air pollutant emission, water pollution, and noise pollution has considerable influence on the financial aspect of sustainability because removing them and controlling their impacts on environment and human health is very difficult and expensive. Moreover, preserving natural resources and wildlife habitat also is a complicated and expensive process that can be controlled by using a renewable source of energy from electromagnetic energy harvesting technology.

\section{Potential Challenges and Limitations}

Like other technologies, electromagnetic energy harvesting has its own challenges and limitations, as well as pros and cons. While the prototype mechanisms in this study successfully demonstrated acceptable performance in laboratory experiments, field experiments under real conditions still need to be undertaken. Moreover, it will be necessary to increase the power output by optimizing the design in future studies in order to extend the range of facilities that can be operated with the generated power. Evaluation of the performance of the mechanisms under different traffic conditions to optimize the design before its field installation should be continued. Depending on the installation location, the load magnitude, traffic volume, and environmental conditions will change; thus, introducing a systematic pattern of design based on real traffic and environment conditions is important. 
In addition, although the evaluation showed promising benefits of the technology for supporting sustainable transportation, the assessment was qualitative, and a quantitative study on the effect of the technology will provide more comprehensive understanding. Further, measuring the impact of a more optimized version of the technology on transportation sustainability will be more realistic.

\section{Conclusions and Summary}

Electromagnetic energy harvester prototypes with two different mechanisms were examined in this study. Both mechanisms used the energy of passing vehicles to generate electrical power within the pavement. Laboratory experimental tests were conducted to examine the capability of each mechanism to generate power under different loading conditions. The performance of both mechanisms in laboratory experimental tests showed promise as a source of renewable energy for roadway infrastructures. The maximum root mean squares of power output were $0.43 \mathrm{~W}$ and $0.04 \mathrm{~W}$ for the cantilever and rotational mechanism while the maximum peak power outputs were $2.8 \mathrm{~W}$ and $0.25 \mathrm{~W}$, respectively. The amount of generated power output is considerable in comparison with other current energy harvesting technologies in roadways. These mechanisms showed a potential to become the main electromagnetic energy harvester in roadways. However, the power output must increase by further optimizing the design and utilizing the components at a larger size and scale than that used in this preliminary examination. In addition, further studies are needed to examine the performance of the proposed mechanisms to generate power under real traffic loading conditions and to endure those loading conditions.

Furthermore, the potential benefits of using the electromagnetic energy harvester prototypes to promote sustainability in transportation were evaluated. As discussed, using electromagnetic energy harvesting can impact transportation sustainability significantly. However, it is important to keep in mind that this study was only a preliminary evaluation, and several factors can change the output of the technology on actual roadways. Therefore, further study involving detailed and quantitative evaluations is needed.

Author Contributions: Conceptualization, M.G. and S.D.; Methodology, M.G.; Formal analysis, M.G.; investigation, M.G., S.A.T., and M.K.; writing — original draft preparation, M.G.; writing—review and editing, S.D.; supervision, S.D.; funding acquisition, S.D.

Funding: Financial support for this research was provided by CPS Energy and the Tran-SET Regional University Transportation Center.

Acknowledgments: The authors would like to acknowledge the assistance of Thomas Keehan of the UTSA College of Engineering, who helped with the fabrication of the prototype.

Conflicts of Interest: The contents of this paper reflect the views of the authors who are solely responsible for the facts and accuracy of the data presented herein and do not necessarily reflect the official views or policies of any agency or institute. This paper does not constitute a standard, specification, nor is it intended for design, construction, bidding, contracting, tendering, certification, or permit purposes. Trade names were used solely for information purposes and not for product endorsement, advertisement, promotions, or certification.

\section{References}

1. Deakin, E. Sustainable Development \& Sustainable Transportation: Strategies for Economic Prosperity, Environmental Quality, and Equity; University of California at Berkeley: Berkeley, CA, USA, 2001.

2. Banister, D. Unsustainable Transport: City Transport in the New Century; Routledge: London, UK, 2005.

3. Litman, T.; Burwell, D. Issues in sustainable transportation. Int. J. Glob. Environ. Issues 2006, 6, 331-347. [CrossRef]

4. Beatley, T. The Many Meanings of Sustainability: Introduction to a Special Issue of JPL; Sage Publications: Thousand Oaks, CA, USA, 1995.

5. Quaddus, M.A.; Siddique, M. Modelling sustainable development planning: a multicriteria decision conferencing approach. Environ. Int. 2001, 27, 89-95. [CrossRef]

6. Chang, Y.-T.; Zhang, N.; Danao, D.; Zhang, N. Environmental efficiency analysis of transportation system in China: A non-radial DEA approach. Energy Policy 2013, 58, 277-283. [CrossRef] 
7. Park, Y.S.; Lim, S.H.; Egilmez, G.; Szmerekovsky, J. Environmental efficiency assessment of US transport sector: A slack-based data envelopment analysis approach. Transp. Res. Part D Transp. Environ. 2018, 61, 152-164. [CrossRef]

8. Zhou, J. Sustainable transportation in the US: A review of proposals, policies, and programs since 2000. Front. Archit. Res. 2012, 1, 150-165. [CrossRef]

9. Black, W.R. Sustainable transportation: A US perspective. J. Transp. Geogr. 1996, 4, 151-159. [CrossRef]

10. Kuang, X.; Zhao, F.; Hao, H.; Liu, Z. Assessing the Socioeconomic Impacts of Intelligent Connected Vehicles in China: A Cost-Benefit Analysis. Sustainability 2019, 11, 3273. [CrossRef]

11. Schulte, J.; Ny, H. Electric Road Systems: Strategic Stepping Stone on the Way towards Sustainable Freight Transport? Sustainability 2018, 10, 1148. [CrossRef]

12. Wang, L. Framework for Evaluating Sustainability of Transport. System in Megalopolis and its Application. IERI Procedia 2014, 9, 110-116. [CrossRef]

13. Gransberg, D.D.; Tighe, S.L.; Pittenger, D.; Miller, M.C. Sustainable pavement preservation and maintenance practices. In Climate Change, Energy, Sustainability and Pavements; Springer: Berlin, Germany, 2014; pp. $393-418$.

14. Haghshenas, H.; Vaziri, M. Urban sustainable transportation indicators for global comparison. Ecol. Indic. 2012, 15, 115-121. [CrossRef]

15. Haghshenas, H.; Vaziri, M.; Gholamialam, A. Evaluation of sustainable policy in urban transportation using system dynamics and world cities data: A case study in Isfahan. Cities 2015, 45, 104-115. [CrossRef]

16. Gilbert, R.; Irwin, N.; Hollingworth, B.; Blais, P. Sustainable transportation performance indicators (STPI). Transp. Res. Board (TRB) CD ROM 2003, 1-20.

17. Steg, L.; Gifford, R. Sustainable transportation and quality of life. J. Transp. Geogr. 2005, 13, 59-69. [CrossRef]

18. Jha, M.K.; Ogallo, H.G.; Owolabi, O. A quantitative analysis of sustainability and green transportation initiatives in highway design and maintenance. Proc.-Soc. Behav. Sci. 2014, 111, 1185-1194. [CrossRef]

19. Richardson, B.C. Sustainable transport: analysis frameworks. J. Transp. Geogr. 2005, 13, 29-39. [CrossRef]

20. Newman, P.; Kenworthy, J. Sustainability and Cities: Overcoming Automobile Dependence; Island Press: Washington, DC, USA, 1999.

21. Gudmundsson, H. Indicators and Performance Measures for Transportation, Environment and Sustainability in North America: Report from a German Marshall Fund Fellowship 2000 Individual Study Tour October 2000; National Environmental Research Institute: Nagpur, India, 2001.

22. Hansson, L.; Nerhagen, L. Regulatory Measurements in Policy Coordinated Practices: The Case of Promoting Renewable Energy and Cleaner Transport in Sweden. Sustainability 2019, 11, 1687. [CrossRef]

23. Wang, K.; Yu, S.; Zhang, W. China's regional energy and environmental efficiency: A DEA window analysis based dynamic evaluation. Math. Comput. Model. 2013, 58, 1117-1127. [CrossRef]

24. Wu, J.; Zhu, Q.; Chu, J.; Liu, H.; Liang, L. Measuring energy and environmental efficiency of transportation systems in China based on a parallel DEA approach. Transp. Res. Part D Transp. Environ. 2016, 48, 460-472. [CrossRef]

25. Ning, D.; Wang, R.; Zhang, C. Numerical simulation of a dual-chamber oscillating water column wave energy converter. Sustainability 2017, 9, 1599. [CrossRef]

26. Hendrickson, C.; Cicas, G.; Matthews, S.H. Transportation sector and supply chain performance and sustainability. Transp. Res. Rec. 2006, 1983, 151-157. [CrossRef]

27. Bilan, Y.; Streimikiene, D.; Vasylieva, T.; Lyulyov, O.; Pimonenko, T.; Pavlyk, A. Linking between Renewable Energy, CO2 Emissions, and Economic Growth: Challenges for Candidates and Potential Candidates for the EU Membership. Sustainability 2019, 11, 1528. [CrossRef]

28. Wang, C.; Zhao, J.; Li, Q.; Li, Y. Optimization design and experimental investigation of piezoelectric energy harvesting devices for pavement. Appl. Energy 2018, 229, 18-30. [CrossRef]

29. Xie, Y.; Wu, S.-J.; Yang, C.-J. Generation of electricity from deep-sea hydrothermal vents with a thermoelectric converter. Appl. Energy 2016, 164, 620-627. [CrossRef]

30. Lu, Z.; Zhang, H.; Mao, C.; Li, C.M. Silk fabric-based wearable thermoelectric generator for energy harvesting from the human body. Appl. Energy 2016, 164, 57-63. [CrossRef]

31. McKinley, I.M.; Lee, F.Y.; Pilon, L. A novel thermomechanical energy conversion cycle. Appl. Energy 2014, 126, 78-89. [CrossRef] 
32. Zhoy, Z.-Y.; Ren, L.W.; Yang, H.Y.; Liu, J.Z.; Chu, K.D.; Weng, J.P.; Yu, Z.W. Effect of short-term acumagnetotherapy on diabetic kidney disease in patients with type II diabetes and study on the molecular mechanism. World J. Acupunct. Moxib. 2015, 25, 1-10. [CrossRef]

33. Guldentops, G.; Nejad, A.M.; Vuye, C.; Rahbar, N. Performance of a pavement solar energy collector: Model development and validation. Appl. Energy 2016, 163, 180-189. [CrossRef]

34. Vocca, H.; Neri, I.; Travasso, F.; Gammaitoni, L. Kinetic energy harvesting with bistable oscillators. Appl. Energy 2012, 97, 771-776. [CrossRef]

35. Izadgoshasb, I.; Lim, Y.Y.; Vasquez Padilla, R.; Sedighi, M.; Novak, J.P. Performance Enhancement of a Multiresonant Piezoelectric Energy Harvester for Low Frequency Vibrations. Energies 2019, 12, 2770. [CrossRef]

36. Tao, K.; Yi, H.; Tang, L.; Wu, J.; Wang, P.; Wang, N.; Hu, L.; Fu, J.; Miao, J.; Chang, H. Piezoelectric ZnO thin films for 2DOF MEMS vibrational energy harvesting. Surf. Coat. Technol. 2019, 359, 289-295. [CrossRef]

37. Izadgoshasb, I.; Lim, Y.Y.; Tang, L.; Padilla, R.V.; Tang, Z.S.; Sedighi, M. Improving efficiency of piezoelectric based energy harvesting from human motions using double pendulum system. Energy Convers. Manag. 2019, 184, 559-570. [CrossRef]

38. Shu, Z.R.; Li, Q.S.; He, Y.C.; Chan, P.W. Observations of offshore wind characteristics by Doppler-LiDAR for wind energy applications. Appl. Energy 2016, 169, 150-163. [CrossRef]

39. Orrego, S.; Shoele, K.; Ruas, A.; Doran, K.; Caggiano, B.; Mittal, R.; Kang, S.H. Harvesting ambient wind energy with an inverted piezoelectric flag. Appl. Energy 2017, 194, 212-222. [CrossRef]

40. Roshani, H.; Jagtap, P.; Dessouky, S.; Montoya, A.; Papagiannakis, A.T. Theoretical and Experimental Evaluation of Two Roadway Piezoelectric-Based Energy Harvesting Prototypes. J. Mater. Civ. Eng. 2017, 30, 04017264. [CrossRef]

41. Walubita, L.; Sohoulande Djebou, D.; Faruk, A.; Lee, S.; Dessouky, S.; Hu, X. Prospective of societal and environmental benefits of piezoelectric technology in road energy harvesting. Sustainability 2018, 10, 383. [CrossRef]

42. Pascual-Muñoz, P.; Castro-Fresno, D.; Serrano-Bravo, P.; Alonso-Estébanez, A. Thermal and hydraulic analysis of multilayered asphalt pavements as active solar collectors. Appl. Energy 2013, 111, 324-332. [CrossRef]

43. Datta, U.; Dessouky, S.; Papagiannakis, A. Harvesting Thermoelectric Energy from Asphalt Pavements. Transp. Res. Rec. J. Transp. Res. Board 2017, 2628, 12-22. [CrossRef]

44. Wang, L.; Park, J.; Zhou, W.; Zuo, L. A Large-Scale On-Road Energy Harvester from Highway Vibration. In Proceedings of the ASME 2016 International Design Engineering Technical Conferences and Computers and Information in Engineering Conference, Charlotte, NC, USA, 21-24 August 2016; American Society of Mechanical Engineers: New York, NY, USA, 2016.

45. Efthymiou, C.; Santamouris, M.; Kolokotsa, D.; Koras, A. Development and testing of photovoltaic pavement for heat island mitigation. Sol. Energy 2016, 130, 148-160. [CrossRef]

46. Lee, K.; Correia, A. Investigation of Novel Methods to Harvest Solar Energy from Asphalt Pavements. A Research Report to Korean Institute of Construction Technology; University of Rhode Island: Kingston, RI, USA, 2010.

47. Wardlaw, J.L.; Karaman, I.; Karsilayan, A. Low-power circuits and energy harvesting for structural health monitoring of bridges. IEEE Sens. J. 2013, 13, 709-722. [CrossRef]

48. Duarte, F.; Ferreira, A. Energy harvesting on road pavements: state of the art. Proc. Inst. Civ. Eng. Energy 2016, 169, 1-12. [CrossRef]

49. Chiarelli, A.; Al-Mohammedawi, A.; Dawson, A.R.; Garcia, A. Construction and configuration of convection-powered asphalt solar collectors for the reduction of urban temperatures. Int. J. Therm. Sci. 2017, 112, 242-251. [CrossRef]

50. Nasir, D.S.; Hughes, B.R.; Calautit, J.K. A CFD analysis of several design parameters of a road pavement solar collector (RPSC) for urban application. Appl. Energy 2017, 186, 436-449. [CrossRef]

51. Gao, Q.; Huang, Y.; Li, M.; Liu, Y.; Yan, Y.Y. Experimental study of slab solar collection on the hydronic system of road. Sol. Energy 2010, 84, 2096-2102. [CrossRef]

52. Faisal, F.; Wu, N.; Kapoor, K. Energy harvesting in pavement from passing vehicles with piezoelectric composite plate for ice melting. In Active and Passive Smart Structures and Integrated Systems 2016; International Society for Optics and Photonics (SPIE): Bellingham, WA, USA, 2016. 
53. Han, C.; Wu, G.; Yu, B.X. Performance Analyses of Geothermal and Geothermoelectric Pavement Snow Melting System. J. Energy Eng. 2018, 144, 04018067. [CrossRef]

54. Chen, M.; Wu, S.; Wang, H.; Zhang, J. Study of ice and snow melting process on conductive asphalt solar collector. Sol. Energy Mater. Sol. Cells 2011, 95, 3241-3250. [CrossRef]

55. Xu, H.; Wang, D.; Tan, Y.; Zhou, J.; Oeser, M. Investigation of design alternatives for hydronic snow melting pavement systems in China. J. Clean. Prod. 2018, 170, 1413-1422. [CrossRef]

56. Yu, W.; Wang, D.; Tan, Y.; Zhou, J.; Oeser, M. State of the art and practice of pavement anti-icing and de-icing techniques. Sci. Cold Arid Reg. 2014, 6, 14-21.

57. Mirzanamadi, R.; Hagentoft, C.-E.; Johansson, P. An analysis of hydronic heating pavement to optimize the required energy for anti-icing. Appl. Therm. Eng. 2018, 144, 278-290. [CrossRef]

58. Jiang, W.; Yuan, D.; Xu, S.; Hu, H.; Xiao, J.; Sha, A.; Huang, Y. Energy harvesting from asphalt pavement using thermoelectric technology. Appl. Energy 2017, 205, 941-950. [CrossRef]

59. Pan, P.; Wu, S.; Xiao, Y.; Liu, G. A review on hydronic asphalt pavement for energy harvesting and snow melting. Renew. Sustain. Energy Rev. 2015, 48, 624-634. [CrossRef]

60. Papagiannakis, A.; Kaphle, R.; Khalili, M. Improving Thermal Properties of Asphalt Concretes. In Advances in Materials and Pavement Prediction; CRC Press: Boca Raton, FL, USA, 2018; pp. 557-560.

61. Mallick, R.B.; Chen, B.-L.; Bhowmick, S. Harvesting energy from asphalt pavements and reducing the heat island effect. Int. J. Sustain. Eng. 2009, 2, 214-228. [CrossRef]

62. Santamouris, M. Using cool pavements as a mitigation strategy to fight urban heat island-A review of the actual developments. Renew. Sustain. Energy Rev. 2013, 26, 224-240. [CrossRef]

63. Hudak, N.S.; Amatucci, G.G. Small-scale energy harvesting through thermoelectric, vibration, and radiofrequency power conversion. J. Appl. Phys. 2008, 103, 5. [CrossRef]

64. García-Olivares, A.; Solé, J.; Osychenko, O. Transportation in a 100\% renewable energy system. Energy Convers. Manag. 2018, 158, 266-285. [CrossRef]

65. Eom, H.J. Faraday's Law of Induction. In Primary Theory of Electromagnetics; Springer: New York, NY, USA, 2013; pp. 95-111.

66. Xie, J.; Zuo, L. Dynamics and control of ocean wave energy converters. Int. J. Dyn. Control 2013, 1, $262-276$. [CrossRef]

67. Leijon, M.; Danielsson, O.; Eriksson, M.; Thorburn, K.; Bernhoff, H.; Isberg, J.; Sunberg, I.; Ivanova, I.; Sjostedt, E.; Agren, O.; et al. An electrical approach to wave energy conversion. Renew. Energy 2006, 31, 1309-1319. [CrossRef]

68. Polinder, H.; Damen, M.; Gardner, F. Design, modelling and test results of the AWS PM linear generator. Int. Trans. Electr. Energy Syst. 2005, 15, 245-256. [CrossRef]

69. Oliveira-Pinto, S.; Rosa-Santos, P.; Taveira-Pinto, F. Electricity supply to offshore oil and gas platforms from renewable ocean wave energy: Overview and case study analysis. Energy Convers. Manag. 2019, 186, 556-569. [CrossRef]

70. Iqbal, M.; Khan, F.U. Hybrid vibration and wind energy harvesting using combined piezoelectric and electromagnetic conversion for bridge health monitoring applications. Energy Convers. Manag. 2018, 172, 611-618. [CrossRef]

71. Rome, L.C.; Flynn, L.; Goldman, E.M.; Yoo, T.D. Generating electricity while walking with loads. Science 2005, 309, 1725-1728. [CrossRef]

72. Liu, M.; Lin, R.; Zhou, S.; Yu, Y.; Ishida, A.; McGrath, M.; Kennedy, B.; Hajj, M.; Zuo, L. Design, simulation and experiment of a novel high efficiency energy harvesting paver. Appl. Energy 2018, 212, 966-975. [CrossRef]

73. Wang, W.; Cao, J.; Zhang, N.; Lin, J.; Liao, W.H. Magnetic-spring based energy harvesting from human motions: Design, modeling and experiments. Energy Convers. Manag. 2017, 132, 189-197. [CrossRef]

74. Zhang, L.B.; Dai, H.L.; Yang, Y.W.; Wang, L. Design of high-efficiency electromagnetic energy harvester based on a rolling magnet. Energy Convers. Manag. 2019, 185, 202-210. [CrossRef]

75. Li, Z.; Zuo, L.; Kuang, J.; Luhrs, G. Energy-harvesting shock absorber with a mechanical motion rectifier. Smart Mater. Struct. 2012, 22, 025008. [CrossRef]

76. Wang, J.; Lin, T.; Zuo, L. High efficiency electromagnetic energy harvester for railroad application. In Proceedings of the ASME 2013 International Design Engineering Technical Conferences and Computers and Information in Engineering Conference, Portland, OR, USA, 4-7 August 2013; American Society of Mechanical Engineers: New York, NY, USA, 2013. 
77. Phillips, K.J. Simulation and Control System of a Railroad Track Power Harvesting Device. Master's Thesis, Faculty of The Graduate College, University of Nebraska-Lincoln, Lincoln, NE, USA, August 2011.

78. Pourghodrat, A. Energy Harvesting Systems Design for Railroad Safety. Master's Thesis, Faculty of The Graduate College, University of Nebraska-Lincoln, Lincoln, NE, USA, August 2011.

79. Zhang, X.; Zhang, Z.; Pan, H.; Salman, W.; Yuan, Y.; Liu, Y. A portable high-efficiency electromagnetic energy harvesting system using supercapacitors for renewable energy applications in railroads. Energy Convers. Manag. 2016, 118, 287-294. [CrossRef]

80. Gholikhani, M.; Tahami, S.A.; Dessouky, S. Harvesting Energy from Pavement-Electromagnetic Approach. In MATEC Web of Conferences; EDP Sciences: Paris, France, 2019.

81. Garcia-Pozuelo, D.; Gauchia, A.; Olmeda, E.; Diaz, V. Bump modeling and vehicle vertical dynamics prediction. Adv. Mech. Eng. 2014, 6, 736576. [CrossRef]

82. Kattan, L.; Tay, R.; Acharjee, S. Managing speed at school and playground zones. Accid. Anal. Prev. 2011, 43, 1887-1891. [CrossRef] [PubMed]

83. Partodezfoli, M.; Rezaey, A.; Baniasad, Z.; Rezaey, H. A novel speed-breaker for electrical energy generation suitable for elimination of remote parts of power systems where is near to roads. J. Basic Appl. Sci. Res. 2012, 2, 6285-6292.

84. Wang, L.; Todaria, P.; Pandey, A.; O’Connor, J.; Chernow, B.; Zuo, L. An Electromagnetic Speed Bump Energy Harvester and Its Interactions with Vehicles. IEEE/ASME Trans. Mechatron. 2016, 21, 1985-1994. [CrossRef]

85. Todaria, P.; Wang, L.; Pandey, A.; O'Connor, J.; McAvoy, D.; Harrigan, T.; Chernow, B.; Zou, L. Design, modeling and test of a novel speed bump energy harvester. In SPIE Smart Structures and Materials+ Nondestructive Evaluation and Health Monitoring; International Society for Optics and Photonics (SPIE): Bellingham, WA, USA, 2015.

86. Gholikhani, M.; Nasouri, R.; Tahami, S.A.; Legette, S.; Dessouky, S.; Montoya, A. Harvesting kinetic energy from roadway pavement through an electromagnetic speed bump. Appl. Energy 2019, 250, 503-511. [CrossRef]

87. Wang, L.; Ban, J.; Wang, L.; Park, J.; Zhou, W.L. On-Road Energy Harvesting for Traffic Monitoring. 2014. Available online: https://www.utrc2.org/sites/default/files/Final-Report-On-Road-Energy-Harvesting.pdf (accessed on 7 September 2019).

88. Sarma, B.S.; Jyothi, V.; Sudhir, D. Design of Power Generation Unit Using Roller Mechanism. IOSR J. Electr. Electron. Eng. (IOSR-JEEE) 2014, 9, 55-60. [CrossRef]

89. Obeid, H.H.; Jaleel, A.K.; Hassan, N.A. Design and Motion Modeling of an Electromagnetic Hydraulic Power Hump Harvester. Adv. Mech. Eng. 2014, 6, 150293. [CrossRef]

90. Zhang, Z.; Zhang, X.; Rasim, Y.; Wang, C.; Du, B.; Yuan, Y. Design, modelling and practical tests on a high-voltage kinetic energy harvesting $(\mathrm{EH})$ system for a renewable road tunnel based on linear alternators. Appl. Energy 2016, 164, 152-161. [CrossRef]

91. Halim, M.A.; Rantz, R.; Zhang, Q.; Gu, L.; Yang, K.; Roundy, S. An electromagnetic rotational energy harvester using sprung eccentric rotor, driven by pseudo-walking motion. Appl. Energy 2018, 217, 66-74. [CrossRef]

92. Aswathaman, V.; Priyadharshini, M. Every speed breaker is now a source of power. In Proceedings of the 2010 International Conference on Biology, Environment and Chemistry IPCBEE, Hong Kong, China, 28-30 December 2010.

93. Goodey, D.; Fidlar, A.; Denawakage Don, V.; Hudnell, D.; Pemberton, R.; Azzouz, M.S.; Brink, J. A Pneumatic Multi-Dome Active Energy Harvesting System. In ASME 2016 International Mechanical Engineering Congress and Exposition; American Society of Mechanical Engineers: New York, NY, USA, 2016.

94. Ullah, K.M.; Ahsan-uz-Zaman, K.M.; Hosen, S.; Khan, R.H.; Parvin, S. Electrical power generation through speed breaker. In Proceedings of the 9th International Conference on Electrical and Computer Engineering (ICECE), Dhaka, Bangladesh, 20-22 December 2016; IEEE: Piscataway, NJ, USA, 2016.

95. Park, P.; Choi, G.S.; Rohani, E.; Song, I. Optimization of Thermoelectric System for Pavement Energy Harvesting; CRC Press: Boca Raton, FL, USA, 2014; pp. 1827-1838.

96. Papagiannakis, A.T.; Montoya, A.; Dessouky, S.; Helffrich, J. Development and Evaluation of Piezoelectric Prototypes for Roadway Energy Harvesting. J. Energy Eng. 2017, 143, 04017034. [CrossRef] 
97. Lee, R.J.; Sener, I.N. Transportation planning and quality of life: Where do they intersect? Transp. Policy 2016, 48, 146-155. [CrossRef]

98. Buehler, R.; Pucher, J. Making public transport financially sustainable. Transp. Policy 2011, 18, 126-138. [CrossRef]

(c)

(C) 2019 by the authors. Licensee MDPI, Basel, Switzerland. This article is an open access article distributed under the terms and conditions of the Creative Commons Attribution (CC BY) license (http://creativecommons.org/licenses/by/4.0/). 